BLS 34, No 1 2008. DOI: http://dx.doi.org/10.3765/bls.v34i1.3577

(published by the Berkeley Linguistics Society and the Linguistic Society of America)

\title{
A Typological Approach to the Split Scope Readings of Negative Indefinites ${ }^{1}$
}

\author{
MICHELLE ST-AMOUR \\ University of Toronto
}

\section{Introduction}

It has been well documented in the literature that the German determiner kein 'no', and its Dutch counterpart geen give rise to several ambiguities when they appear in constructions with other scope-bearing elements (SBE). These ambiguities arise when the negative indefinites (NIs) such as kein interact with other quantifiers or are embedded under intensional verbs, as can be seen in (1) and (2), respectively:

Alle Ärtze haben kein Auto

(Jacobs 1980)

all doctors have no car
a. 'All doctors are such that they have no car'
b. \#'No car is such that all doctors have it'
c. 'Not all doctors have a car'

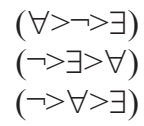

(2)

Du musst keine Krawatte anziehen

(de Swart 2000) you must no tie wear
a. 'It must be the case that you wear no tie'
(must $>\rightarrow>\exists$ )
b. ?'There is no tie such that you must wear it'
$(\neg>\exists>$ must $)$
c. 'It is not the case that you must wear a tie'
$(\neg>$ must $>\exists)$

The universal quantifier and the intensional verb can either scope above the negative indefinite (1a and $2 a$ ) or below the negative indefinite ( $1 b$ and $2 b)$. The so-called 'split-scope' reading occurs when another scope-bearing element appears in between the two operators of the negative indefinite. In such construc-

\footnotetext{
${ }^{1}$ Many thanks to Michela Ippolito and the 2007-2008 Forum students at the University of Toronto for many discussions and comments. Thanks to Andrea Gualmini for comments on an earlier version of this paper. A special thanks to my German informants: Eva Dobler, Cornelia Loos and Maire Noonan. This work was partially supported by a Standard Research Grant from the Social Sciences \& Humanities Research Council of Canada (SSHRC) to Andrea Gualmini.
} 


\section{Michelle St-Amour}

tions the negative operator has split away from the existential quantifier (1c and 2c).

In this paper, I present two previous analyses that aim to account for these split-scope readings. I then highlight why the previous proposals cannot account for new data, namely fronting data from German. In section 4, I propose an alternative approach to negative indefinites. Section 5 presents and discusses another characteristic of the split-scope data: it is absent from negative concord languages. Section 6 concludes the paper.

\section{Previous Approaches}

Many theories have been put forth in an attempt to explain this phenomenon, arguing whether or not negative indefinites undergo 'lexical decomposition'. Lexical decomposition is the process that decomposes a complex lexeme into its component parts; these smaller elements then occupy two separate nodes in a syntactic representation and are completely syntactically autonomous.

De Swart (2000), among others, has proposed that lexical decomposition must be avoided in order to maintain lexical integrity. As an alternative, de Swart (2000) accounts for the data by appealing to a complex notion of higher-order quantification such as quantification over properties (de Swart, 2000).

Other theories, such as Penka and Zeijlstra (2005), argue that in order to have a split-scope reading, the negative indefinites must undergo lexical decomposition; thus, the two operators ( $O p \neg$ and $\exists$ ) occupy separate syntactic nodes.

\subsection{Non-Lexical Decomposition: de Swart (2000)}

De Swart (2000) argues against lexical decomposition, an approach to split-scope readings first proposed by Jacobs (1980), which states that negative indefinites such as kein undergo decomposition in the syntax and thus each operator (negative and existential) occupy separate nodes in a syntax. Since the operators are different nodes in the tree, they are syntactically independent, and thus are able to take scope independently of each other in order to yield split-scope readings.

De Swart (2000) argues against this approach, stating that if one appeals to lexical decomposition for kein based on data such as (3) and (4), then one should also appeal to lexical decomposition for other monotone decreasing quantifiers such as at most two and few because a split reading also arises in such contexts:

(3) Tom needs at most two blankets

a. 'What Tom needs to have is at most two blankets' (need $\left.>_{\neg}>\exists_{>_{2}}\right)$

b. 'There are at most two blankets such that Tom needs to have them' $\left(\neg>\exists_{>2}>\right.$ need $)$

c. 'It is not the case that Tom needs to have more than two blankets'

$$
\left(\neg>\text { need }>\exists_{>2}\right)
$$

(4) Ze hoeven wenig verpleegkundigen te ontslaan [Dutch]

They need few nurses to fire 


\section{A Typological Approach to Split-Scope Readings}

a. \#'It is necessary for them to fire few nurses' (need $>\neg>\exists_{>\text {small } \#)}$

b. 'For a group consisting of few nurses, it is the case that they must fire the group' $\left(\neg>\exists_{>\text {small }}>\right.$ need $)$

c. 'It is not necessary for them to fire more than a small number of nurses'

$$
\left(\neg>\text { need }>\exists_{>\text {small } \#)}\right.
$$

If we take the split reading of (1) and (2) as evidence that kein can be decomposed into $O p \neg$ and $\exists$ (following de Swart, 2000) then we should conclude that the split-scope reading in (3) suggests that at most two can be decomposed into $O p \neg$ and more than two.

Similarly, the split-scope reading in (4) suggests that few should be decomposed into $O p \neg$ and more than a small number of. De Swart argues that such an approach should be abandoned because it leads to a "proliferation of decomposition rules".

De Swart (2000) proposes an alternative account for the split-scope readings that avoids lexical decomposition and instead involves quantification over individuals and quantification over properties:

$$
\begin{array}{ll}
\text { Hanna sucht kein Buch } & \text { [German] } \\
\begin{array}{ll}
\text { H. seeks no book } & \\
\text { a. 'What Hanna seeks is no book' } & (\text { seek }>\neg>\exists) \\
\quad \text { Seek }\left(\mathrm{h},{ }^{\wedge} \lambda x \neg \operatorname{Book}(x)\right) & \\
\text { b. 'There exists no book such that Hanna seeks it' } & (\neg>\exists>\text { seek }) \\
& \neg x(\operatorname{Book}(x) \wedge \text { Seek }(h, x))
\end{array}
\end{array}
$$

\section{[German]}

For a sentence such as (5), the narrow and wide scope negative indefinite readings can be accounted for if we quantify over individuals. (5a) expresses that Hanna is a not-book seeker, in other words, she seeks things that are not books. The weak $\mathrm{NP}$ in predicative position expresses quantification over the individual and this gives rise to the de dicto reading. Wide scope quantification over individuals in (5b) yields the de re reading, which expresses that there is not book such that Hanna seeks it. The split reading can be accounted for if we quantify over the property of book-seeking, as in (6):

$$
\begin{array}{ll}
\text { Hanna sucht kein Buch } & {[\text { German }]} \\
\text { H. seeks no book } & (\neg>\text { seek }>\exists) \\
\text { a. no book } & =\lambda P \neg \exists \mathrm{P}\left(\mathrm{P}=\wedge \lambda \mathrm{y}(\operatorname{Book}(\mathrm{y})) \wedge^{\vee} P(\mathrm{P})\right)
\end{array}
$$

\footnotetext{
${ }^{2}$ De Swart (2000) also argues against the lexical decomposition approach based on monotone increasing quantifier, such as at least two, which do not exhibit split-scope readings. The lexical decomposition approach, according to de Swart (2000), cannot capture this dichotomy between monotone decreasing and monotone increasing quantifiers. For reasons of space, I will not discuss this issue here.
} 


\section{Michelle St-Amour}

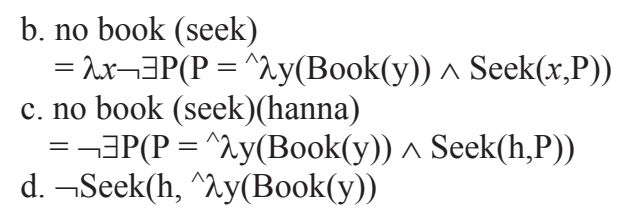

Because intensional verbs such as seek are denoted as a relation between individuals and properties, seek is of the right type to be an argument of a higher-order quantifier. The derivation in (6) expresses that there is no property that is identified with the book property, and is such that Hanna seeks it. This generates the appropriate split-scope reading.

Therefore, according to de Swart (2000), all weak NPs in predicative position have three possible derivations: a wide scope interpretation in terms of quantification over individuals, a narrow scope interpretation in terms of quantification over a property and a wide scope interpretation in terms of quantification over properties.

\subsection{Lexical Decomposition: Penka and Zeijlstra (2005)}

Penka and Zeijlstra (2005) argue against de Swart (2000) in favour of a lexical decomposition approach to negative indefinites based on idiomatic data, among other things. They argue that the non-lexical decomposition approaches such as de Swart (2000) cannot account for the split-scope reading that arises in idioms containing kein, such as (7):

Mir kannst du keinen Bären aufbinden
me.DAT can you no bear up-tie
'You can't fool me'

De Swart (2000), according to Penka and Zeijlstra, cannot account for the split reading of (7) because in order for higher-order quantification to apply, the negative indefinite must undergo Quantifier Raising $(\mathrm{QR})$, which is not permitted for idioms. It is necessary for the idiom to be interpreted 'en bloc' at LF, which de Swart's (2000) account will not permit. The only way that de Swart (2000) can generate the split reading is to apply higher-order quantification, which would force the existential to be interpreted outside of the idiomatic expression.

As a solution to the split-scope reading of idioms, Penka and Zeijlstra (2005) argue for lexical decomposition of negative indefinites, in which the $O p \neg$ and the $\exists$ occupy different nodes on the tree. The lexical item kein, as Penka and Zeijlstra (2005) argue, is a complex structure that is already "prefabricated in the lexicon" (Penka and Zeijlstra 2005:5), as in (8): 


\section{A Typological Approach to Split-Scope Readings}

(8)

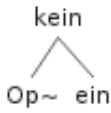

By assuming that kein is a complex lexical item that enters the derivation as a unit and contains two syntactically autonomous nodes, it will allow Penka and Zeijlstra to account for the data in (1) - (2) and the idioms in (7). In order to generate the narrow scope reading, the $O p \neg$ and $\exists$ will be interpreted in the scope of the modal at LF:

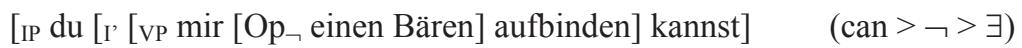

The complex negative indefinite kein may QR to adjoin to IP in order to account for the other two readings. Once the negative indefinite has undergone $\mathrm{QR}$, the two distinct nodes, $O p \neg$ and $\exists$, can be interpreted either high or low. To yield the wide scope negative indefinite reading, both the $O p \neg$ and $\exists$ are interpreted high, as in (10):

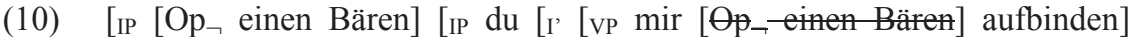
kannst]]

$$
(\neg>\exists>\text { can })
$$

The split reading can now be easily accounted for because the $O p \neg$ and the $\exists$ need not be interpreted in the same copy. The $O p \neg$ may be interpreted high, while the $\exists$ is interpreted low ${ }^{3}$ :

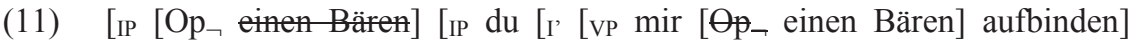
kannst]]

The same approach can be used to account for the non-idiomatic expressions, such as (2), repeated here:

Du musst keine Krawatte anziehen

(de Swart 2000)

you must no tie wear
a. 'It must be the case that you wear no tie'
(must $>\neg>\exists$ )
b. ?'There is no tie such that you must wear it'
$(\neg>\exists>$ must $)$
c. 'It is not the case that you must wear a tie'
$(\neg>$ must $>\exists)$

The same as for the idiomatic expressions, the narrow scope NI reading is the result of interpreting the NI in its base-generated position (13). The wide scope NI reading is obtained by QR (14). The split-scope reading is the result of QR, then

\footnotetext{
${ }^{3}$ The unavailability of an existential wide scope with a negative narrow scope reading is ruled out on independent grounds, as proposed by Beck (1996).
} 
Michelle St-Amour

interpreting the negation in the higher copy and the existential in the lower copy (15):

(13) $\quad\left[\mathrm{IP}\left[\mathrm{I}\left[\mathrm{vP}\right.\right.\right.$ du $\left[\mathrm{Op}_{\neg}\right.$ eine Krawatte $]$ anziehen $]$ musst $\left.]\right]$ (must $>\neg>\exists$ )

(14) $\left[\right.$ IP $\left[\mathrm{Op}_{\neg}\right.$ eine Krawatte] [I [IP du [Op_eine Krawatte] anziehen] musst]] $(\neg>\exists>$ must $)$

[IP [Op $\neg$ eine Krawatte] [I [IP du [Op_ eine Krawatte] anziehen] musst]]

$$
(\neg>\text { must }>\exists)
$$

In the next subsection, I highlight some problems for de Swart (2000) and Penka and Zeijlstra's (2005) theory of negative indefinites when considering fronting data from German. In section 4, I propose a new approach to account for the splitscope readings and the problematic fronting data.

\section{Problematic Data: Fronting}

While Penka and Zeijklstra's (2005) analysis is able to account for the split-scope reading of negative indefinites and idioms, it faces problems in light of other data, namely fronting. The problem lies in the fact that the phrase ein Buch ('a book') can move to the front of the structure. Therefore, the existential ein and the noun Buch should form a constituent that excludes negation, so they are able to undergo fronting together while stranding negation as in (18) (from den Besten and Webelhuth (1990) with modifications):

(16) Hans will kein Buch lesen

H. want no book read

'It is not the case that Hans wants to read a book' $\quad(\neg>$ want $>\exists)$

(17) Ein Buch will Hans nicht lesen

a book want $\mathrm{H}$. not read

'It is not the case that Hans wants to read a book' $\quad(\neg>$ want $>\exists)$

However, if the negative indefinite kein is one complex lexeme that enters the derivation 'as a unit', as Penka and Zeijlstra (2005) argue, then the existential and the noun will never form a constituent without also including the negation, as illustrated in (18), which is required for the fronting data found in (17): 
(18)

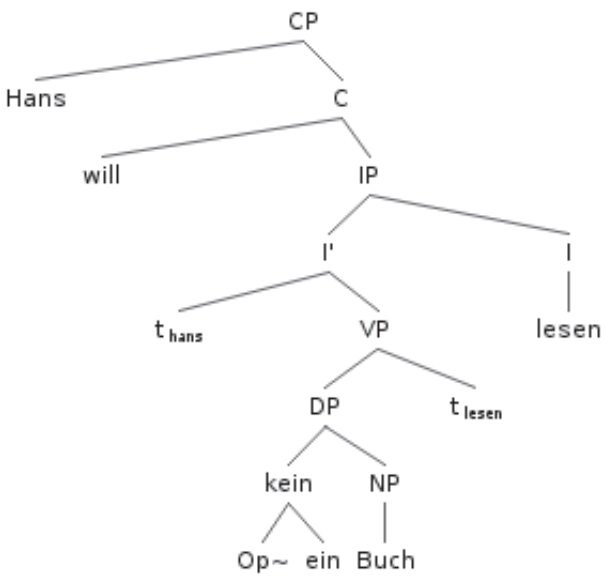

If Penka and Zeijlstra's approach is correct, there is no way to account for the construction in (17) because the DP ein Buch is not a constituent, and thus, will not be able to front.

The same problems arise with de Swart's (2000) higher-order quantification approach. Although she does not explicitly illustrate how NIs is merged into the structure, it is clear that her analysis would require the negative indefinite kein to be one lexical item. De Swart (2000) argues against the idea of lexical decomposition, in which the lexical item occupies more than one node in the syntax, but would assume, like Penka and Zeijlstra (2005), that kein is one lexical item that contains a negation and an existential. If this is the case, we are once again unable to account for the fronting data. If kein is one lexical item, then the existential from the negative indefinite will never form a constituent with the noun, while excluding the negation, which is required for the fronting data found in (17).

Therefore, in order to account for the fronting structures presented here, we must propose an alternative approach to negative indefinites. The aim of section 4 is to present a possible solution to this problem, although some details of the new account are left for further research.

\section{An Alternative Account for Split-Scope Readings}

As we saw in sections 2 and 3, previous analyses of negative indefinites are able to capture the split-scope readings that arise when these lexemes appear in constructions with other scope bearing elements, yet they are unable to account for other data, such as idioms in the case of de Swart (2000) and fronting in the case of both de Swart (2000) and Penka and Zeijlstra (2005). In this section, I propose an alternative approach that will seek to avoid these problems.

Instead of assuming that negative indefinites are complex lexical items that enter the derivation with internal structure, à la Penka and Zeijlstra (2005), I 


\section{Michelle St-Amour}

propose here that each operator is merged into the structure independently. If the negative operator and the existential are adjacent at PF, a fusion rule applies in order to yield kein in German and geen in Dutch:

\section{PF Representation:}

[CP Hans [C musst [IP $t_{\text {Hans }}\left[\mathrm{vP}[\mathrm{DP} \mathbf{O p}\urcorner\left[\mathrm{DP}\right.\right.$ ein Buch]] lessen] $\left.\left.\left.\mathrm{t}_{\text {musst }}\right]\right]\right]$

\section{kèin}

This approach affords us at least two advantages: it can account for the fronting data found in (17) and the idiomatic data found in (7).

If the negative operator and the existential of the negative indefinite enter into the derivation separately, the negation can be a DP adjunct, ensuring that the existential ein and the noun phrase Buch are a constituent ${ }^{4}$ :

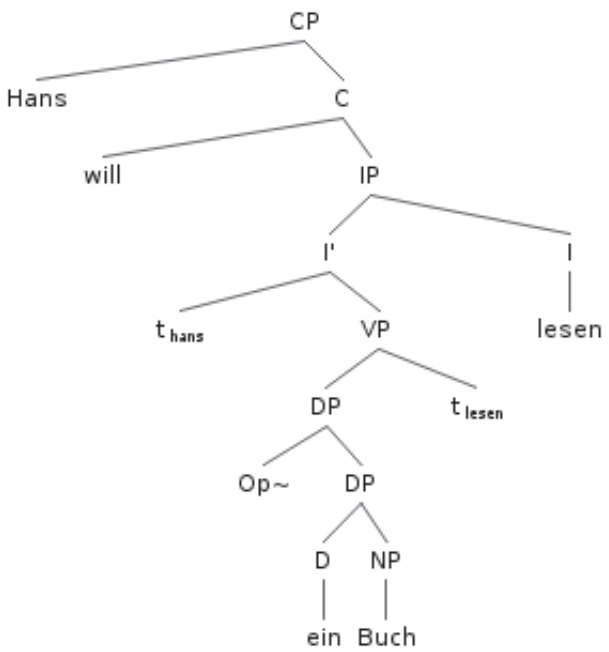

It is now possible to derive the fronted structure in (17) above, repeated here as (21), which caused problems for de Swart (2000) and Penka and Zeijlstra (2005):

(21) Ein Buch will Hans nicht lesen

a book want $\mathrm{H}$. not read

'It is not the case that Hans wants to read a book' $\quad(\neg>$ want $>\exists)$

\footnotetext{
${ }^{4}$ This follows previous proposals which argue that constituent negation is an adjunct (Newell 2005, among others).
} 


\section{A Typological Approach to Split-Scope Readings}

As for idioms, I argue that a copy theory of movement and partial spell-out will be able account for the split-scope readings of idioms with negative indefinites, much like Penka and Zeijlstra (2005). For reasons of space, I ommitt the details of this here. It suffices to say that a proposal for idioms such as Penka and Zeijlstra's (2005) with the small modifications outlined above, namely that negative indefinites are a result of two separately merged operators as opposed to a complex lexeme that undergoes lexical decomposition, will account for the idiomatic data by avoiding the flaws of de Swart's (2000) account, as detailed by Penka and Zeijlstra (2005), while also accounting for the fronting data.

Lastly, the approach I propose here avoids the complex higher-order quantification over properties that is required for de Swart (2000) and the internal structure in the lexicon required for Penka and Zeijlstra's (2005) representation of negative indefinites as a complex lexeme. By abandoning these complex notions in favour of the approach I have proposed here, we find ourselves left with a simpler system, which is a welcome result.

\section{The Absence of Split-Scope Readings in NC Languages}

As we have seen above, n-words in double negation (DN) languages, where two (or more) negative elements cancel each other out to yield a positive reading, as in (22), exhibit split-scope readings (de Swart 2000), as in (23):

$$
\begin{aligned}
& \text { Alle Ärtze nicht haben kein Auto } \\
& \text { all doctors not have no car } \\
& \text { 'All doctors do not have no car' } \\
& \text { ='All doctors have a car' }
\end{aligned}
$$

[German]

(23) Alle Ärtze haben kein Auto

all doctors have no car

'Not all doctors have a car'

However, this reading is absent from negative concord (NC) languages, where two or more negative elements yield a negative reading:

Jean a pas vu personne

[Québécois French]

J. did not see nobody

'Jean didn't see anybody'

(NC)

(25) $\mathrm{Tu}$ dois parler à personne

[Québécois French]

you must talk to no one

'It must be the case that you talk to no one'

(must $>\neg>\exists$ )

*'It is not the case that you must talk to someone'

$*(\neg>$ must $>\exists)$ 


\section{Michelle St-Amour}

$\mathrm{Tu}$ dois rien manger

you must nothing eat

'It must be the case that you eat nothing'

(must $>\neg>\exists$ )

*'It is not the case that you must eat something' $\quad *(\neg>$ must $>\exists)$

This fact is often over-looked in theories of split-scope readings and research on negative constituents ( $\mathrm{n}$-words) in negative concord languages. The absence of split-scope readings in languages such as Québécois French raises several important questions, including: what is responsible for this typological patter? In what follows, I begin to explore these issues and tease apart the difference between the two systems of multiple negation and the behaviour of n-words with respect to split-scope readings; yet some questions will be left for further research.

On one hand, double negation languages allow split-scope readings because each n-word is an instance of a negative operator that is a DP adjunct, as argued above. Therefore, this operator is independent from the existential and free to take widest scope in order to give rise to split-scope readings.

On the other hand, negative concord languages do not allow split-scope readings. But why are these readings not generated in NC languages? Is it a special property of the negative operator? Are n-words different in $\mathrm{NC}$ than they are in DN? What does the absence of split-scope readings tell us about negative operators and negative indefinites in NC languages? What mechanism is present in double negation languages that generates split-scope readings and is absent from negative concord languages?

Following Zeijlstra (2004), I assume that n-words in negative concord languages are inherently non-negative and thus lack a negative operator. They are syntactically marked for negation and carry a [UNEG] feature that must be checked against an [iNEG] feature:

Nessuno ha telefonato

[Italian]

nobody has called

'Nobody called'

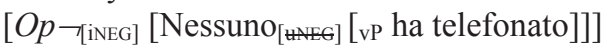

(28) Non ha telefonato a nessuno

neg has called to nobody

'He hasn't called anybody'

$\left[\mathrm{NegP}\left[\mathrm{non}_{[\mathrm{iNEG}]}[\mathrm{vP}\right.\right.$ ha telefonato a nessuno $\left.[\mathrm{HNEG}]]\right]$

In (27), a null negative operator licenses the non-negative n-word pre-verbally. In the case of (28), the sentential negation non licenses the post-verbal n-word nessuno 'nobody'. As can be seen by the [uNEG] feature on the n-words in (27) (28), each negative indefinite in negative concord languages are inherently nonnegative, and thus, does not contain a negative operator. Instead, the negative reading, according to Penka and Zeijlstra (2005), comes from one instance of a 


\section{A Typological Approach to Split-Scope Readings}

negative operator, which licenses the n-words with its [iNEG] feature. This [iNEG] cannot take scope independently, similar other licensing operators, otherwise an intervention affect arises (Chierchia 1995):

$$
\begin{array}{ll}
\text { Every student didn't come to the party } & (\neg \forall) \\
\text { Every student didn't do anything } & (\forall \neg \exists), *(\neg \forall \exists)
\end{array}
$$

Whatever mechanism allows the negation to take wide scope in (29) is blocked when it is acting as an NPI-licensor, as in (30), which can only license the NPI locally (Chierchia 1995). If another SBE intervenes at LF between the NPI and the licensor, a Beck Effect arises, thus that reading is not available (Beck 1996).

Returning to NIs and the absence of split-scope readings in NC languages, we can apply the same type of reasoning used for licensors and locality conditions in order to account for the lack of split-scope readings. Since n-words in NC languages carry [uNEG] and must be properly licensed, they are similar to NPIs and thus are sensitive to Beck Effects. Therefore, the licensing negative operator cannot take scope above another SBE, while the n-word takes scope below, because the [UNEG] feature will not be properly locally licensed. As a result, splitscope readings of negative indefinites, which are the preferred reading in double negation languages, do not arise in negative concord languages.

\section{Conclusion}

In this paper, I have argued that previous proposals of split-scope readings of negative indefinites, such as de Swart (2000) and Penka and Zeijlstra (2005), cannot account for fronting in German. As a result, I proposed an alternative account in which NIs are not one lexical item, as previous analyses assume, but are the result of a PF fusion of two separately merged operators.

We are now equipped to answer some of the questions raised in the previous section regarding the typological pattern of split-scope readings and systems of multiple negation. The typological pattern of split-scope readings can be boiled down to the properties of the negative operator and the negative indefinites, along with the relationship that exists between them. More specifically, n-words in NC languages are inherently non-negative and must be checked by a negative operator; meanwhile, n-words in DN languages are the result of a PF fusion rule and are inherently negative. Therefore, when a negative indefinite in NC appears in a construction with negation, a negative reading arises because there is only one instance of a negative operator. This relationship requires local licensing and thus prohibits split-scope readings. When a NI in DN appears in a construction with another negation, on the other hand, a positive reading arises because the negative operator from the sentential negation and the operator from the NI cancel each other out, as in classical logic.

In closing, it is no longer a question of what mechanism is present in DN but absent in $\mathrm{NC}$, but rather what condition is in place in NC yet absent in DN. It is 


\section{Michelle St-Amour}

not the case that some mechanism allows the negative operator of an NI to take independent scope in DN and that that mechanism is not available in NC languages. Rather, it is the locality condition, in which the negative operator must locally license the [uNEG] feature of the NI in NC, that is absent from DN.

There are a few question, however, that remain. How would the proposal for split-scope readings presented here account for the fact that degree phrases, such as at most two and few, also exhibit split-scope readings, as noted in de Swart (2000)? Furthermore, can this proposal make the proper predictions with respect to monotone decreasing quantifiers, which never exhibit split-scope readings? These questions are left for further research.

\section{References}

Beck, Sigrid. 1996. Quantified Structures as Barriers for LF Movement. Natural Language Semantics 4:1-56.

den Besten, Hans, and Gerth Webelhuth. 1990. Stranding. In G. Grewendorf and W. Sternefeld, eds., Scrambling and Barriers, 77-92. Amsterdam: John Benjamins Publishing Company.

Chierchia, Gennaro. 1995. Individual-Level Predicates as Inherent Generics. In G. Carlson and F. Pelletier, eds., The Generic Book. Chicago: University of Chicago Press.

Jacobs, Joachim. 1980. Lexical Decomposition in Montague Grammar. Theoretical Linguistics 7:121-136.

Link, Godehard. 1976. Intensionale semantik. Müchen: Fink.

Newell, Heather. 2005. Bracketing Paradoxes and Particle Verbs: A Late adjunction analysis. In S. Blaho, L. Vicente and E. Schoorlemmer, eds., Proceedings of ConSOLE XIII, 249-272.

Penka, Doris \& Hedde Zeijlstra. 2005. Negative Indefinites in Dutch and German. http://ling.auf.net/lingbuzz/000192

de Swart, Henriëtte. 2000. Scope Ambiguities with Negative Quantifiers. In K. von Heusinger and U. Egli, eds., Reference and Anaphoric Relations, 109132. Dordrecht: Kluwer Academic Publishers.

Michelle St-Amour

University of Toronto

Department of Linguistics

130 St. George Street, room 6076

Toronto, Ontario

M5S 3H1, Canada

michelle.stamour@utoronto.ca 